\title{
DESEMPENHO EMPRESARIAL EM SETORES CONCENTRADOS: UM ESTUDO COMPARATIVO NAS SALINAS DO ESTADO DO RIO GRANDE DO NORTE
}

Data de submissão: $27 / 08 / 2014$ Aceite: 05/10/2016

Rosângela Queiroz Souza Valdevino ${ }^{1}$ Heber José de Moura ${ }^{2}$ Fátima Regina Ney Matos ${ }^{3}$

\section{RESUMO}

$\mathrm{Na}$ atual conjuntura competitiva, os acompanhamentos administrativos e financeiros são essenciais para o estabelecimento dos requisitos necessários a uma eficiente tomada de decisão. Assim, o objetivo deste trabalho foi comparar o desempenho empresarial do setor salineiro do Rio Grande do Norte no período de 2010/2011, com os setores de mineração e serviços hospitalares que também apresentam elevado grau de concentração, segundo classificação baseada nos índices Razão de Concentração (CR) e Herfindahl-Hirschman (HH). A pesquisa foi de natureza quantitativa aplicada em 33 empresas salineiras do Rio Grande do Norte. Para o tratamento dos dados, realizou-se a técnica de análise multivariada de cluster. Quanto aos resultados, foi possível identificar que o setor salineiro foi o que melhor destacou-se financeiramente com crescimento no lucro líquido de $11,11 \%$. Pode-se concluir que, devido à inelasticidade do setor salineiro, o mesmo tem apresentado crescimento no Estado.

Palavras-chave: Desempenho empresarial, setores concentrados, sustentabilidade empresarial, Razão de concentração CR), índice de Herfindahl-Hirschman (HH).

1 Possui graduação em Ciências Contábeis pela Universidade do Estado do Rio Grande do Norte, UERN e mestrado em Administração de Empresas pela Universidade de Fortaleza, UNIFOR. Mossoro - RN. Brasil. E-mail: rosangelaqueiroz84@yahoo.com.br.

2 Possui graduação em Estatística pela Universidade Federal de Pernambuco, UFPE, mestrado em Análise de Sistemas pela Instituto Nacional de Pesquisas Espaciais, INPE e doutorado em Administração de Empresas pela Fundação Getulio Vargas - SP, FGV-SP. Fortaleza - CE. Brasil. E-mail: heberm@unifor.br.

3 Possui graduação em Psicologia pela Universidade Federal do Ceará, UFC, mestrado em Administração pela Universidade Estadual do Ceará, UECE e doutorado em Administração pela Universidade Federal de Pernambuco, UFPE. Natal - RN. Brasil.

E-mail: fneymatos@globo.com 


\section{INTRODUÇÃO}

O mundo empresarial tem passado, atualmente, por inúmeras transformações, as quais têm feito as empresas pensarem estrategicamente em negócios inovadores. Com isso, fatores como concorrência, aceitação dos produtos, marketing e políticas da organização precisam estar bem atreladas para que a organização se mantenha em um mercado exigente e competitivo. Neste sentido, os empresários começaram a rever os seus conceitos e passaram a perceber que precisavam adaptar-se ao mercado globalizado, pois, dessa forma, teriam mais chances de garantir a permanência dos seus produtos e a continuidade das atividades por longo prazo (KIBEREN; MUSIEG; JUMA, 2013).

Segundo Capobiango et al. (2012) é necessário realizar o acompanhamento administrativo/financeiro das empresas, com o propósito de dispor de informações voltadas para a tomada de decisões, tendo em vista que se manter em um mercado mutável e competitivo em relação a bens e serviços não é uma tarefa considerada fácil. Para Oliveira (2011), a análise de concentração em uma organização avalia os efeitos da competição não apenas com relação ao número de empresas envolvidas, mas também ao seu impacto no nível de produção e preços.

Sabe-se que, todos os dias, é necessário tomar decisões nas empresas, para as quais, consequentemente, o gestor carece de suporte, ou seja, de informações que viabilizem o seu trabalho. Um instrumento relevante é composto pelos índices de desempenho econômicos/financeiros, os quais contribuem para prover uma maior visão das variáveis econômicas. A análise dos resultados financeiros faz com que o gestor avalie melhor o negócio, tenha confiança nos investimentos, administre seu capital de giro, pondere a necessidade de usar capital de terceiros e procure soluções para diminuir custos, desenvolvendo ideias inovadoras para os seus produtos (LUNENBURG, 2011).

O controle do desempenho empresarial é responsável pelos resultados gerados sob os aspectos financeiros e não financeiros, considerando que a organização que não controla o seu desempenho, via de regra, não tem condições de avaliar em que patamar se encontra, pois é por meio desse tipo de informação que se torna possível emitir um parecer da saúde empresarial e comparar os resultados com outras empresas do mesmo ramo, observando assim os pontos vulneráveis e fazendo com que os administradores pensem em soluções viáveis para resolver problemas do cotidiano (KEHINDE, 2012).

Conforme Kaplan e Norton (1997), medir o desempenho das empresas é fundamental para a gestão estratégica, tendo em vista que aquilo que não pode ser medido também não pode ser gerenciado.

Diante desse cenário, o objetivo do trabalho é comparar o desempenho empresarial do setor salineiro do Estado do Rio Grande do Norte (RN) no período de 2010/2011, com os setores de mineração e serviços hospitalares que também apresentam elevado grau de concentração, segundo classificação baseada nos índices Razão de Concentração (CR) e Herfindahl-Hirschman (HH). O período definido para a pesquisa baseou-se em dados documentais disponíveis na Revista Exame Melhores e Maiores (2011-2012), para os anos 2010 e 2011, em que são destacadas as regiões Norte e Nordeste.

O estudo traz uma contribuição no sentido de mostrar a relevância de setores concentrados como o salineiro. Caracterizar os setores concentrados é necessário para compreender melhor as suas qualidades específicas, seja em relação a serviços, seja a produtos, averiguando ainda como são representados economicamente e como medem o seu desempenho financeiro e sustentável, o que também é fundamental para o aumento do conhecimento na área. 
O artigo está organizado em cinco partes. Além dessa introdução, no referencial teórico são apresentados os setores concentrados e a medição do desempenho empresarial. Na metodologia, estão a coleta e o tratamento dos dados. Segue-se a análise dos resultados, na qual estão a análise de clusters dos indicadores sociais e financeiros, a comparação intersetorial dos indicadores financeiros e o grau de concentração. Por fim, são apresentadas as considerações finais e as referências.

\section{REFERENCIAL TEÓRICO}

\subsection{Setores concentrados}

Um dos critérios adequados da administração de empresas é o da organização setorial, segundo o qual se tem uma empresa ou grupo com todas as suas partes bem coordenadas, movimentando-se de forma que fiquem ajustadas e também ligadas ao setor de que fazem parte, de modo que formem uma unidade de funcionamento e não um conglomerado de peças separadas. Da mesma forma que há gerenciamento em uma empresa, também deve haver em um setor, de modo que a maioria das soluções encontradas beneficiam todas as empresas que produzem serviços ou bens (GRAHAM, 1997).

Goschin et al. (2009) retratam as ações das atividades econômicas dos setores concentrados em uma determinada região, geralmente em comparação com o resto do campo, enquanto que a concentração geográfica, climática e de mão de obra de uma atividade favorece o desenvolvimento de um grupo de empresas com as mesmas atividades. Isso é o que justifica a concentração de setores em regiões específicas.

Na visão de Carreira e Lopes (2012), a atividade concentrada destaca-se com certos tipos de bens ou serviços e acaba trazendo uma contribuição para o local e proporcionando um crescimento econômico nacional. Fatores como salários, conhecimento, produtividade, crescimento econômico e localização são essenciais para definir a concentração de um setor.

Segundo Tedesco (2012), algumas medidas podem identificar os quesitos que levam um setor a ser concentrado em uma determinada região, tendo ainda como objetivo saber o quanto os gerentes podem explorar o comportamento de um mercado, isto acontece por meio de medidas que usam critérios de ponderação. Normalmente, o nível de concentração de um setor que trabalha com atividade especifica está associado ao aumento de capacidade de produção. $\mathrm{Na}$ concepção de Kupfer e Hasenclever (2012), quanto maior for o grau de concentração, menor se dá a concorrência e maior poderá ser o poder dessas empresas no meio empresarial.

Alguns setores da atividade econômica tem a característica peculiar de apresentar alta concentração, como é o caso dos setores salineiro, de mineração e serviços hospitalares.

Para Bezerra et al. (2012), a produção salineira no Rio Grande do Norte tem maior concentração nos municípios de Macau e Mossoró, que contribuem com cerca de $75 \%$ da produção total do país. Neste Estado, a maior empresa tem uma participação de $40 \%$ na produção total, as duas maiores contribuem com $57,5 \%$ e a participação das seis maiores é de $89,5 \%$ do total. O destino das exportações norte-rio-grandenses é voltado principalmente para a Nigéria e os Estados Unidos que, juntos, absorvem $90 \%$ do sal marinho a granel. A capacidade de refino está mais distribuída, ficando $56 \%$ dela no RN e $44 \%$ no Sul/Sudeste, principalmente em Cabo Frio, no Estado do Rio de Janeiro.

Considerando os dados citados, o setor salineiro é representativo economicamente tanto para o Rio Grande do Norte quanto para o país. Conforme Aguiar (2012), o estado já chegou a exportar um milhão de toneladas, o que é significativo em nível mundial. Em 2012, o volume não 
ultrapassou 200 mil toneladas (Mt). O Programa de Aceleração do Crescimento (PAC) aumentou em oito mil metros quadrados a área de armazenamento do sal e ampliou de $120 \mathrm{Mt}$ para 220 mil a capacidade de estocagem do Porto-Ilha no Rio Grande do Norte. Tudo isso com o objetivo de tornar o terminal mais competitivo e fazer com que navios salineiros de até $75 \mathrm{Mt}$ atraquem no porto. Inaugurada em junho de 2012, a nova estrutura jamais foi usada, devido a uma perda de $20 \%$ na produção das salinas do Estado, o que obrigou o setor a cancelar as exportações. Para quem, em anos anteriores, chegou a exportar mais de $700 \mathrm{Mt}$ de sal, o comércio externo foi reduzido em mais de $50 \%$. De acordo com esses dados, as exportações de sal do RN registram uma curva descendente nesses anos. Em 2007, foram comercializadas $701 \mathrm{Mt}$ de sal marinho a granel, que representaram US\$ 9,3 milhões. Em 2008, a exportação do produto caiu quase $50 \%$, tendo sido de 297 Mt para um faturamento de US\$ 4,7 milhões. Em 2010, voltou a subir e chegou a 741 Mt e US\$ 14 milhões, mas, em 2011, apresentou queda de 38\%, com 398 Mt e US\$ 8,6 milhões. Diante da falta de estoque para exportação, o mercado interno tornou-se prioritário. Com a escassez do produto no mercado devido às fortes chuvas, registrou-se uma valorização no preço do sal, o que, de certa forma, compensou as perdas que os produtores tiveram com o comércio exterior.

Diante desse contexto é possível identificar a existência de outras pesquisas que têm como objeto de estudo o setor salineiro no RN, como a dissertação de Carvalho (2007), que estudou as salinas do RN e investigou as principais características da medição de desempenho empresarial utilizadas pelas empresas.

A dissertação de Alves (2011) teve como objetivo geral verificar o posicionamento das indústrias salineiras em relação à importância da logística como ferramenta estratégica utilizada na minimização dos custos logísticos e na maximização do desempenho econômico-financeiro. Outro trabalho foi à tese de Oliveira (2011) tratou de uma investigação sobre as percepções e as práticas do empresário salineiro acerca da responsabilidade social empresarial.

Outro setor com elevado grau de concentração é o da mineração. De fato, a mineração é um segmento que vem crescendo de forma acelerada no país. Segundo o Instituto Brasileiro de Mineração (IBRAM, 2011), a partir de 2000, a procura por minerais foi intensificada, o que impulsionou o valor da produção brasileira, principalmente nos períodos de 2001 a 2011. Naquele período, o valor da produção mineral teve crescimento de 550\%, saindo de 7,7 bilhões para 50 bilhões de reais, tendo em vista que, de forma geral, no país, o crescimento da produção continua evoluindo entre $10 \%$ e $15 \%$ anualmente nos últimos três anos, garantindo, dessa forma, aumento positivo para 2013. Ainda segundo o IBRAM (2011), os valores previstos, com base em dados coletados em mineradoras, mostraram investimentos expressivos de $\mathrm{R} \$ 68,5$ bilhões para o período de 2011/2015, o que significa um novo recorde na mineração. Com base nos dados acima, observa-se a relevância da atividade de mineração para o país em termos de geração econômica.

Destaca-se também o setor de serviços hospitalares, que é também concentrado, principalmente quando enfoca os planos de saúde privados como Sociedade Cooperativa de Trabalho Médico (UNIMED) e Hospital Antônio Prudente (HAPVIDA). Diante disso. Martins (2011) afirma que no Brasil o setor de planos privados de assistência à saúde envolve mais de quarenta milhões de beneficiários, dos quais aproximadamente $85 \%$ estão ligados a planos de assistência médica com ou sem odontologia e $15 \%$ a planos exclusivamente odontológicos. O setor congrega ainda duas mil empresas operadoras e milhares de prestadores de serviços entre médicos, dentistas e outros profissionais de saúde, em hospitais, laboratórios, clínicas e consultórios. 


\subsection{Medição do desempenho empresarial}

Para Neely e Bourne (2000), no início do século XX, começou a haver uma preocupação quanto à necessidade de realizar a medição empresarial por meio dos indicadores financeiros. As primeiras empresas a utilizarem essas técnicas foram a Dupont e a General Motors, o que as torna pioneiras nessa prática, pois perceberam que, participando de um mercado competitivo, precisavam de um auxílio para tomar decisões seguras.

Na visão de Ghalayini e Noble (1996), o reconhecimento das medidas de desempenho é dividido em duas etapas, sendo a primeira em 1880, em que os indicadores financeiros eram voltados para medir o lucro e a produtividade. Na segunda fase, em 1980, com o crescimento empresarial, ocorreram mudanças e uma evolução, de modo a se perceber que as medidas não atendiam suficientemente às necessidades das organizações. A partir de então, novas medidas financeiras começaram a ser desenvolvidas para atender a um mercado mais exigente e competitivo.

De acordo com Harif, Hoe e Ahmad (2013), no mundo empresarial, com decisões a serem tomadas o tempo todo, o processo de medir é significativo do ponto de vista de questões como: centralização de capital, divisão dos riscos inerentes aos empreendimentos produtivos e monitoramento de projetos. Quando essas funções são controladas e cumpridas, a economia da organização atinge seu nível máximo de efetividade.

A avaliação de desempenho empresarial, conforme Kassai (2002) está relacionada à verificação do cumprimento de obrigações por parte dos empresários responsáveis pelo gerenciamento da organização.

Wanderley et al. (2010) retratam que os métodos de avaliação de desempenho empresarial, que antes baseavam-se apenas em indicadores de caráter contábil e financeiro, não são mais considerados suficientes. E é nesse contexto de mudanças que se explica o surgimento de diversos modelos de mensuração de desempenho, com o propósito de gerenciar eficientemente as informações corporativas (financeiras e não financeiras) que dão suporte à tomada de decisões. As empresas atualmente estão na busca incessante por tais sistemas, gerando assim a necessidade de maiores estudos sobre sistemas de medição de desempenho.

Segundo Menezes, Guimarães e Bido (2011), medir, de uma forma geral, é uma atividade vista como necessária para as organizações, pois o empresário pode mensurar a percepção dos clientes quanto a melhorias organizacionais, comparando com períodos anteriores, bem como medir o tempo dos bens e serviços no mercado, reclamações externas de clientes, custo de cada transação comercial, retorno de investimentos e participação da empresa no comércio.

\section{METODOLOGIA}

A pesquisa tem como foco principal as empresas salineiras do Estado do RN, que, aliás, formam um setor concentrado e representativo no país em termos produtivos. De acordo com o Sindicato do Sal (SIESAL) (2012), o setor é constituído pelo universo de 33 empresas no estado do RN, atuantes e registradas. Foi possível comparar esse setor com empresas de outros setores também concentrados como mineração e serviços hospitalares. As informações sobre esses outros setores foram fornecidas pela Revista Exame Melhores e Maiores $(2011,2012)$ no que se refere aos dados dos anos 2010 e 2011.

Devido à produção de sal depender de condições climáticas, estes são os últimos anos 
mais consistentes, pois a produção salineira começou em 2010, enquanto que a colheita e as vendas deram-se em 2011, fatos que concluem o ciclo salineiro em termos produtivos e de lucratividade, tendo em vista ainda que os dados de tais anos sejam os mais recentes para a coleta de pesquisa.

Quanto à abordagem, trata-se de uma investigação quantitativa. Para Cooper e Schindler (2011), essa abordagem caracteriza-se pelo emprego de quantificação tanto nas modalidades de coleta de informações, quanto no tratamento delas por meio de técnicas estatísticas, desde as mais simples como médias, frequências absolutas e relativas e desvio padrão, até as mais complexas, como a análise de clusters. Para Corrar et al. (2009), a análise de clusters é uma das técnicas de análise multivariada cujo propósito primário é reunir objetos semelhantes, baseando-se nas características destes.

\subsection{Coleta de dados}

Para a coleta primária dos dados, foi feita uma entrevista gravada com os gestores do setor salineiro do Estado do RN, a partir de um roteiro estruturado envolvendo questões abertas e fechadas, as quais procuraram investigar sobre: aspectos relativos à medição de desempenho e sustentabilidade da empresa, índices financeiros e resultados sustentáveis. Tratou-se ainda de um estudo censitário, pois a pesquisa foi realizada em todo o setor salineiro. Quanto ao período de coleta de dados, deu-se de junho de 2012 a dezembro de 2013.

Os dados coletados dos setores de mineração e saúde são exclusivamente financeiros. As informações foram obtidas por intermédio de dados documentais disponíveis na Revista Exame Melhores e Maiores (2011, 2012), para os anos 2010 e 2011 em que são destacadas as regiões Norte e Nordeste. Em relação às empresas de mineração, são cinco: Alunorte, Vale Potássio Nordeste, Mineração Caraíba, Mineração Paragominas e Mineração do Rio Grande do Norte (MRN). Quanto aos serviços hospitalares são três empresas: UNIMED Fortaleza, UNIMED Belém e HAPVIDA Fortaleza. Segundo a referida revista, essas empresas citadas foram destaque em crescimento econômico e financeiro nos anos de 2010 e 2011. Elas foram comparadas com o setor salineiro por apresentarem características semelhantes de concentração nos setores em que atuam.

\subsection{Tratamento dos dados}

Todos os dados da pesquisa foram tabulados no programa estatístico Statistical Package for the Social Sciences - SPSS versão 20. Foram computados valores financeiros do setor salineiro para os anos de 2010 e 2011, levando em consideração as seguintes variáveis: receita bruta, custos e despesas, folha de pagamento, lucro líquido, ativo total, capital de terceiros sobre recursos totais, prazo médio de vendas, prazo médio de renovação de estoque e prazo médio de pagamento das compras. As demais variáveis constituem os indicadores sociais internos e externos, bem como indicadores socioambientais. Esses são encontrados no balanço social e tratam de investimentos sociais em educação, treinamentos profissionais, saúde e de forma geral benefícios sociais que podem ser dentro da empresa ou de forma externa, atuando junto a ações sociais e/ou relacionados ao meio ambiente. Tais apontadores foram avaliados nos referidos anos por estatística descritiva. Para Corrar et al. (2009), a estatística descritiva permite conhecer o menor e o maior valor encontrado em cada variável bem como, determinar a sua média e o seu desvio padrão entre outras medidas. 
A técnica de análise de clusters foi uma ferramenta utilizada no setor salineiro para que fosse observada a similaridade entre as empresas. Segundo Malhotra (2001), a análise de conglomerados ou de clusters é uma técnica usada para classificar objetos em grupos relativamente homogêneos, chamados conglomerados. Para Hair et al. (2005), a análise de clusters constitui um grupo de técnicas multivariadas, cuja finalidade primária é agregar objetos com base nas características que eles possuem. $\mathrm{O}$ agrupamento é feito a partir de um critério predeterminado, ressaltando as similaridades existentes. O critério utilizado foi a análise hierárquica, usada para identificar os grupos de observações, utilizando algarismo que inicia com um aglomerado e combina as observações até formar todo o grupo. $\mathrm{O}$ algarismo usado baseou-se na distância euclidiana.

$$
d(\boldsymbol{x}, \boldsymbol{y})=\sqrt{\sum_{i=1}^{p}\left(x_{i}-y_{i}\right)^{2}}
$$

Tal equação representa a medida de distância usada entre as $p$ variáveis de cada objeto $X$ e Y.

Foi utilizado o teste (Qui-Quadrado) para que fosse observado se as empresas constantes dos clusters 1, 2 e 3 do agrupamento social eram as mesmas que pertenciam aos grupos 1,2 e 3 do agrupamento financeiro

A estatística descritiva foi aplicada também nos setores de mineração e serviços hospitalares, nos anos de 2010 e 2011. As variáveis consideradas foram: lucro líquido ajustado (em US\$), patrimônio líquido ajustado (em US\$), rentabilidade legal (em \%) e Earning Before Interests, Taxes, Depreciation and Amotization (EBITDA) (em US\$). Diante de tais procedimentos foi possível comparar o crescimento do lucro líquido dos três setores objeto de estudo.

Para fechamento do tratamento dos dados, foi investigado o nível de concentração dos setores de sal, mineração e serviços hospitalares, baseando-se nos índices "Razão de Concentração" e "Herfindahl-Hirschman (HH)". Para Resende e Boff (2012), o índice "Razão de Concentração" mede a proporção a partir de um número fixo de empresas do setor e varia de 0 a 100, sendo que, quanto mais próximo de 100, maior a concentração.

Segundo Bain (1968), o índice "Razão de Concentração" pode ser representado pela fórmula:

$$
C r(k)=\sum_{i=1}^{n} P_{i}
$$

Em que:

$n$ = número de firmas que fazem parte do cálculo;

$P_{i}=$ participação da i-ésima firma no mercado.

O índice HH, conforme Kon (1994), é definido pela soma dos quadrados da participação de cada organização em relação ao tamanho total do setor, como segue na fórmula a seguir: 


$$
H H=\sum_{i=1}^{n} P_{i}^{2}
$$

Em que:

$n=$ número de firmas que fazem parte do cálculo;

$P_{i}=$ participação da i-ésima firma no mercado.

Para o cálculo dos índices HH e "Razão de Concentração" foi necessário conhecer a receita de cada empresa e dividi-la pela receita total do setor, obtendo as varáveis $P_{i}$ e $P_{i}{ }^{2}$. Por meio dos resultados, conseguindo dessa forma avaliar o nível de concentração dos setores.

\section{ANÁLISE DOS RESULTADOS}

Foi elaborado um resumo financeiro baseado em valores mínimos, máximos, médias e desvios padrões das variáveis: receita bruta, custo e despesas, folha de pagamento, lucro líquido e ativo total, como pode-se observar na tabela 1, a seguir. Tais variáveis foram analisadas nos aspectos percentuais e reais em relação aos anos de 2010 e 2011.

Tabela 1 - Resumo financeiro da variação de 2011 em relação a 2010

\begin{tabular}{|c|c|c|c|c|c|}
\hline \multicolumn{6}{|c|}{ Resumo Financeiro } \\
\hline Variáveis & $\mathrm{N}$ & Mínimo & Máximo & Média & $\begin{array}{l}\text { Desvio Pa- } \\
\text { drão }\end{array}$ \\
\hline Receita bruta (em \%) & 33 & $-10,00$ & 30,00 & 14,87 & 11,01 \\
\hline Receita bruta (em R\$) & 33 & 00 & $132.677 .712,00$ & $15.599 .324,61$ & $28.690 .700,06$ \\
\hline Custos e despesas (em \%) & 33 &,- 10 & 50,00 & 12,33 & 11,42 \\
\hline Custos e despesas (em R\$) & 33 & $120.000,00$ & $80.937 .980,00$ & $10.439 .635,76$ & $18.242 .623,23$ \\
\hline Folha de pagamento (em \%) & 33 & 00 & 30,00 & 12,30 & 7,39 \\
\hline Folha de pagamento (em $\mathrm{R} \$$ ) & 33 & ,00 & $20.000 .000,00$ & $2.109 .090,10$ & $3.605 .810,51$ \\
\hline Lucro líquido (em \%) & 33 & $-5,00$ & 32,00 & 11,11 & 9,32 \\
\hline Lucro líquido (em R\$̧) & 33 & , 00 & $15.622 .426,00$ & $3.761 .285,64$ & $4.311 .962,63$ \\
\hline Ativo total $(\mathrm{em} \%)^{*}$ & 32 & $-12,00$ & 86,00 & 11,95 & 17,52 \\
\hline Ativo total (em $\mathrm{R} \$)^{* *}$ & 26 & $1.760 .000,00$ & $130.000 .000,00$ & $16.311 .576,92$ & $28.096 .225,22$ \\
\hline
\end{tabular}

Fonte: Elaborada pelos autores (2013). *Uma empresa não respondeu. **Seis empresas não responderam.

A variação da receita bruta em percentuais foi o primeiro elemento a ser verificado de 2010 para 2011, conforme observa-se na tabela 1 . A variação média da receita bruta no setor salineiro foi de $(14,87 \%)$ em relação a 2010 . O menor valor foi de $-10,00 \%$ o que pode ser entendido como um decréscimo, tendo em vista que a produção diminui em 2011. Isso pode ser evidenciado no valor máximo de 30\%. O aumento da receita bruta foi de $\mathrm{R} \$ 132.677 .712,00$, com média de $\mathrm{R} \$ 15.599 .324,61$, tendo ainda como desvio padrão $\mathrm{R} \$ 28.690 .700,06$. Isto representa alta variabilidade nas receitas das empresas. Para Gartner (2010), ao mesmo tempo em que as informações financeiras são utilizadas no interior das companhias, elas também alimentam 
análises e processos decisórios.

Os dados ilustrados na tabela 1 mostram que mesmo diante da crise de produção que o setor salineiro enfrentou, obteve-se crescimento médio de 15\%, segundo as informações colhidas. Este desenvolvimento ocorreu devido ao aumento do preço do produto em 2011.

Os custos e despesas avaliam os gastos que a atividade salineira tem para se manter funcionando. Avaliando o percentual médio, constata-se um acréscimo de 12,33\% de 2010 para 2011. Ressalta-se que o valor máximo foi de $50 \%$ indicando expressivo aumento de custos/ despesas de uma empresa particular. Com relação aos valores absolutos, o custo médio foi de $\mathrm{R} \$ 10.439 .635,76$, tendo o desvio padrão de $\mathrm{R} \$ 18.242 .623,23$. Diante dos dados é notório que houve um crescimento percentual semelhante entre receitas e custos.

A folha de pagamento do setor também foi avaliada em percentuais e reais, apresentando um crescimento médio de 12,30\% correspondendo a um acréscimo de $R \$ 2.109 .090,10$. O desvio padrão foi de $\mathrm{R} \$ 3.605 .810,51$. A maior parte da folha de pagamento refere-se ao grande número de empregados na área de produção de sal.

O menor decréscimo percentual encontrado na variável lucro líquido foi de $-5 \%$ em relação a 2011, enquanto o aumento máximo foi de $32 \%(R \$ 15.622 .426,00)$ devido ao equilíbrio causado pela redução da produção e elevação do preço. Observa-se que o setor como um todo aumentou os seus lucros entre 2010 e 2011, mostrando crescimento no período.

Quanto ao ativo total, que se refere a todos os bens e direitos de que a empresa dispõe, o setor salineiro cresce $11,95 \%$ em média, representando uma magnitude financeira de cerca de 16 milhões de reais.

Ao analisar a tabela 2, abaixo, observa-se que o capital de terceiros foi outro item levado em consideração. Na análise relativa a 2010, o valor médio foi de 4,95\%, e em 2011 aumentou $5,45 \%$ representado aumento do nível de endividamento. A análise dessa variável é relevante, pois, segundo Matarazzo (2010), do ponto de vista financeiro, quanto maior a utilização de capitais de terceiros, menor será a liberdade de decisões financeiras. Diante disso, as salinas norte-rio-grandenses apresentam baixo nível de endividamento financeiro.

Tabela 2 - Resumo financeiro dos indicadores anuais

\begin{tabular}{|c|c|c|c|c|c|}
\hline \multicolumn{6}{|c|}{ Indicadores Anuais } \\
\hline Variáveis & $\mathrm{N}$ & Mínimo & Máximo & Média & Desvio Padrão \\
\hline $\begin{array}{l}\text { Capital de terceiros sobre recursos totais (endi- } \\
\text { vidamento) \% (2010) }\end{array}$ & 33 & ,00 & 47,40 & 4,95 & 8,47 \\
\hline $\begin{array}{l}\text { Capital de terceiros sobre recursos totais (endi- } \\
\text { vidamento) \% (2011) }\end{array}$ & 33 & ,00 & 38,80 & 5,45 & 7,88 \\
\hline Prazo médio de vendas em 2010 (dias) & 33 & ,00 & 240,00 & 54,79 & 51,57 \\
\hline Prazo médio de vendas em 2011 (dias) & 33 & 30,00 & 240,00 & 57,55 & 49,69 \\
\hline $\begin{array}{l}\text { Prazo médio de renovação de estoque em } \\
\qquad 2010 \text { (dias) }\end{array}$ & 33 & ,00 & 180,00 & 85,73 & 65,93 \\
\hline $\begin{array}{l}\text { Prazo médio de renovação de estoque em } \\
2011 \text { (dias) }\end{array}$ & 33 & 30,00 & 180,00 & 87,88 & 64,03 \\
\hline $\begin{array}{l}\text { Prazo médio de pagamento das compras em } \\
\qquad 2010 \text { (dias) }\end{array}$ & 33 & ,00 & 90,00 & 40,10 & 21,51 \\
\hline $\begin{array}{l}\text { Prazo médio de pagamento das compras em } \\
2011 \text { (dias) }\end{array}$ & 33 & 7,00 & 90,00 & 42,64 & 18,86 \\
\hline
\end{tabular}

Fonte: Elaborada pelos autores (2013). 
Outra variável analisada na tabela 2 foi o prazo médio de vendas, que, em 2010, teve média de 54,79 dias, apresentando pequena variação em 2011.

Quanto ao prazo médio de renovação de estoque, também não houve variação entre 2010 e 2011, indicando que os prazos de venda foram mantidos no período. Diante dos resultados, a renovação de estoque apresenta uma situação quase estática em relação aos anos analisados.

No que se refere à variável prazo médio de pagamento das compras, em 2010, constatou-se o valor médio de 40,09 dias e desvio padrão de 21,51. Em 2011, esse desvio reduziu para 18,86 dias, e a média subiu para 42,64 dias. Diante das comparações entre os dois anos em análise, o prazo médio de vendas teve uma variação apenas de 2,55 pontos percentuais, o que não mostra modificações significativas no período.

Os indicadores sociais internos e externos fazem parte do balanço social e tratam dos investimentos sociais que a empresa destina para educação, saúde, recuperação florestal, treinamentos profissionais, eventos beneficentes, entre outros que envolvem de forma interna ou externa os funcionários e sociedade, conforme ilustrado na tabela 3, abaixo.

Tabela 3 - Resumo estatístico dos indicadores sociais

\begin{tabular}{|c|c|c|c|c|c|}
\hline \multicolumn{7}{|c|}{ Indicadores Sociais } \\
\hline Variáveis & $\mathrm{N}$ & Mínimo & Máximo & Média & Desvio Padrão \\
\hline Indicadores sociais internos (em 2010) & 33 &, 00 & 2,00 &, 80 &, 72 \\
\hline Indicadores sociais internos (em 2011) & 33 &, 00 & 2,00 &, 80 &, 72 \\
\hline Indicadores sociais externos (em 2010) & 33 &, 00 & 2,00 &, 53 &, 65 \\
\hline Indicadores sociais externos (em 2011) & 33 &, 00 & 2,00 &, 53 &, 65 \\
\hline Indicadores sociais ambientais (em 2010) & 33 &, 00 & 2,50 & 1,12 &, 72 \\
\hline Indicadores sociais ambientais (em 2011) & 33 &, 00 & 2,50 & 1,12 &, 72 \\
\hline
\end{tabular}

Fonte: Elaborada pelos autores (2013).

Os indicadores sociais internos em 2010 e 2011 tiveram valores iguais a 0,80\% enquanto que os indicadores externos foram menores $(0,53 \%)$ nos dois anos evidenciados. Já os de natureza socioambiental foram representados por maiores valores de $1,12 \%$. Para Khanafiah e Situngkir (2011), os empresários ainda precisam perceber o valor de investir em projetos de interesse social interno e externo como educação, saúde e proteção ambiental, fatores estes que estão relacionados diretamente com a imagem da empresa.

\subsection{Análise de clusters dos indicadores sociais e financeiros}

Em seguida, foi analisado o grau de similaridade das empresas, baseando-se na análise de conglomerado.

O procedimento baseou-se nas variáveis "indicadores sociais internos, externos e ambientais", tendo sido aplicado para os anos 2010 e 2011, conforme ilustrado na tabela 4, abaixo. 
Tabela 4 - Centróides dos clusters - indicadores sociais

\begin{tabular}{|c|c|c|c|}
\hline Indicadores Sociais & \multicolumn{3}{|c|}{ Cluster } \\
\cline { 2 - 4 } & 1 & 2 & 3 \\
\hline Internos - 2010 &, 22 & 1,21 & 2,00 \\
\hline Internos - 2011 &, 22 & 1,21 & 2,00 \\
\hline Externos - 2010 &, 04 &, 79 & 2,00 \\
\hline Externos - 2011 &, 04 &, 79 & 2,00 \\
\hline Ambientais - 2010 &, 53 & 1,61 & 2,00 \\
\hline Ambientais - 2011 &, 53 & 1,61 & 2,00 \\
\hline
\end{tabular}

Fonte: Elaborada pelos autores (2013).

Com base na análise da tabela 4, observa-se que o primeiro cluster dá maior ênfase aos indicadores sociais ambientais valorados em 0,53 , enquanto que os índices sociais externos mostraram baixo grau de preocupação $(0,04)$. 0 indicador social interno teve valor situado entre os dois anteriores de $(0,22)$. De forma geral, o primeiro cluster apresenta valores poucos expressivos. No segundo agrupamento, os indicadores foram maiores, tendo em vista que as variáveis sociais internas e ambientais apresentaram grau de importância similar respectivamente de $(1,21$ e 1,61), enquanto o identificador social externo teve valor de 0,79 .

Diante das variáveis selecionadas, o indicador de maior investimento, tanto no cluster 1 quanto no 2, foi o indicador socioambiental, enquanto os demais alternaram o seu nível de importância nas empresas. Para Melo, Almeida e Santana (2012), os investimentos em indicadores sociais e ambientais têm feito parte das organizações, tornando-se cada vez mais evidentes, principalmente, devido às demandas de governo e sociedade que valorizam tais questões na economia.

O terceiro cluster apresenta as empresas que dão maior ênfase ao ambiente interno, externo e o socioambiental. De acordo com Donaire (2011), as empresas ainda estão em um processo de reconhecimento, pois no que se referem às questões sociais e ambientais, algumas organizações entendem que investir em tais variáveis constituem em estratégia para uma melhor gestão.

A tabela 5, a seguir, mostra o resultado do teste ANOVA aplicado entre os três clusters, indicando a obtenção de significância estatística para as diferenças entre os grupos, em relação a todos os tipos de indicadores.

Tabela 5 - ANOVA - indicadores sociais

\begin{tabular}{|c|c|c|c|c|c|c|}
\hline \multirow{2}{*}{ Indicadores Sociais } & \multicolumn{2}{c|}{ Cluster } & \multicolumn{2}{c|}{ Erro } & F & Sig. \\
\cline { 2 - 7 } & $\begin{array}{c}\text { Quadrados } \\
\text { Médios }\end{array}$ & GL & $\begin{array}{c}\text { Quadrados } \\
\text { Médios }\end{array}$ & GL & \\
\hline Indicadores sociais internos em 2010 & 6,058 & 2 &, 145 & 30 & 41,904 &, 000 \\
\hline Indicadores sociais internos em 2011 & 6,058 & 2 &, 145 & 30 & 41,904 &, 000 \\
\hline Indicadores sociais externos em 2010 & 5,639 & 2 &, 070 & 30 & 81,047 &, 000 \\
\hline Indicadores sociais externos em 2011 & 5,639 & 2 &, 070 & 30 & 81,047 &, 000 \\
\hline Indicadores sociais ambientais em & 5,596 & 2 &, 177 & 30 & 31,533 &, 000 \\
\hline 2010
\end{tabular}




\begin{tabular}{|c|c|c|c|c|c|c|}
\hline $\begin{array}{c}\text { Indicadores sociais ambientais em } \\
2011\end{array}$ & 5,596 & 2 &, 177 & 30 & 31,533 &, 000 \\
\hline
\end{tabular}

Fonte: Elaborada pelos autores (2013).

Ao considerar um nível de significância de 0,05, contata-se que as diferenças entre os três indicadores nos três agrupamentos encontrados podem ser considerados significativos, conforme ilustrado na tabela 5.

Em seguida, realizou-se análise de conglomerados usando variáveis financeiras, tendo sido obtidos os resultados a seguir. As variáveis referem-se a:

percentual de variação de receita bruta entre 2010 e 2011;

percentual de variação do lucro líquido entre 2010 e 2011;

percentual de variação do ativo total entre 2010 e 2011.

Tabela 6 - Centróides dos clusters - indicadores financeiros

\begin{tabular}{|c|c|c|c|}
\hline Cluster Financeiro & \multicolumn{3}{|c|}{ Cluster } \\
\cline { 2 - 4 } & $\mathbf{1}$ & $\mathbf{2}$ & $\mathbf{3}$ \\
\hline Receita bruta em \% &, 00 & 7,25 & 21,59 \\
\hline Lucro líquido em \% &, 00 & 4,92 & 15,42 \\
\hline Ativo total em \% & 68,00 & 1,08 & 12,97 \\
\hline
\end{tabular}

Fonte: Elaborada pelos autores (2013).

Com base na observação da tabela 6, acima, constata-se que o primeiro cluster caracteriza-se pelo grupo de empresas com elevado percentual de ativo total, mas que não informaram receitas e lucros.

O agrupamento 2 é composto pelas empresas que tiveram maiores receitas e lucros, mas que apresentam baixos investimentos no ativo total. É possível constatar que tais empresas conseguem gerar bons resultados com pouco investimento no ativo total, o que denota eficácia.

Finalmente, o último grupo indica as empresas que tiveram maior desempenho financeiro nas três variáveis.

Para Devinney, Yip e Johnson (2009), as empresas que criam valor acima da média de suas indústrias ganham vantagens competitivas. Coff (2010) também destaca que, ao aumentar razoavelmente os seus lucros, a empresa acaba tendo também vantagem competitiva e pode lograr outros resultados em desempenho financeiro e organizacional.

Diante das análises elaboradas foi possível comparar os resultados sociais e financeiros obtidos. Observou-se que as empresas constantes dos clusters 1, 2 e 3 do agrupamento social não são as mesmas que pertencem aos grupos 1, 2 e 3 do agrupamento financeiro, mas a significância estatística ocorreu ao nível de $12 \%$ como mostra o resultado do teste $c^{2}$.

$\mathrm{H}_{0}$ - Os Clusters são independentes.

$\mathrm{H}_{1}$ - Os Clusters são dependentes.

O $p$-value resultante foi 0,12 como este valor está acima do padrão de $5 \%$ não se pode afirmar que os clusters têm mesma distribuição, ou seja, são independentes.

A tabela 7, a seguir, indica que os três clusters podem ser considerados como significativamente diferenciados em relação aos indicadores financeiros. 
Tabela 7 - ANOVA - indicadores financeiros

\begin{tabular}{|c|c|c|c|c|c|c|}
\hline \multirow{2}{*}{ Variáveis } & \multicolumn{2}{c|}{ Cluster } & \multicolumn{2}{c|}{ Erro } & F \\
& Qung. & \\
& Quadrados Médios & GL & Quadrados Médios & GL & & \\
\hline Receita bruta em \% & 975,525 & 2 & 66,589 & 29 & 14,650 &, 000 \\
\hline Lucro líquido em \% & 514,850 & 2 & 47,553 & 29 & 10,827 &, 000 \\
\hline Ativo total em \% & 3859,513 & 2 & 61,764 & 29 & 62,488 &, 000 \\
\hline
\end{tabular}

Fonte: Elaborada pelos autores (2013).

Para Hair et al. (2005), as variáveis analisadas demonstram seu grau de significância ao apresentar erro tipo 1 menor que 0,05, que implica valores acima das variáveis "receita bruta \%", "lucro líquido \%" e "ativo total \%" são significativos.

\subsection{Comparação intersetorial dos indicadores financeiros}

Para a comparação dos setores de mineração e saúde foi aplicada estatística descritiva com o intuito de descobrir valores médios e desvio padrão baseados nas seguintes variáveis: lucro líquido ajustado (em US\$), patrimônio líquido ajustado (em US\$), rentabilidade legal (em \%) e EBITDA (em US\$), conforme ilustrado na tabela 8, abaixo.

Setor: Mineração. Anos: 2010-2011

Tabela 8 - Estatística descritiva dos indicadores financeiros - setor mineração

\begin{tabular}{|c|c|c|c|}
\hline \multicolumn{2}{|c|}{ Indicadores Financeiros } & Média & Desvio Padrão \\
\hline Dados Financeiros 2010 & N & 64,70 & 50,90 \\
\hline Lucro líquido em US\$ & 3 & 1149,20 & 1537,99 \\
\hline Patrimônio líquido ajustado em US\$ & 3 & 13,77 & 22,17 \\
\hline Rentabilidade legal em \% & 3 & 164,43 & 91,78 \\
\hline EBITDA em US\$ & 3 & Média & Desvio Padrão \\
\hline Dados Financeiros 2011 & N & 5,70 & 61,72 \\
\hline Lucro líquido em US\$ & 5 & 884,02 & 1029,48 \\
\hline Patrimônio líquido ajustado em US\$ & 5 & 11,10 & 18,18 \\
\hline Rentabilidade legal em \% & 5 & 91,88 & 82,68 \\
\hline
\end{tabular}

Fonte: Elaborada pelos autores (2013).

Como pode ser observado na tabela 8, o setor de mineração mostra uma redução em todas as variáveis financeiras consideradas: lucro líquido ajustado (em US\$), patrimônio líquido ajustado (em US\$), rentabilidade legal (\%) e EBITDA (em US\$) nos anos de 2010 para 2011.

No caso do setor de saúde, ao observar a tabela 9, a seguir, nota-se que, com exceção do patrimônio líquido, todos os demais indicadores financeiros reduziram-se de 2010 para 2011.

Setor: Saúde. Anos: 2010-2011

ReV. AdM. UFSM, SANTA MARIA, V. 11, NÚMERo 3, P. 637-656, 2018 
Tabela 9 - Estatística descritiva dos indicadores financeiros - setor saúde

\begin{tabular}{|c|c|c|c|}
\hline \multicolumn{2}{|c|}{ Indicadores Financeiros } & Média & Desvio Padrão \\
\hline Dados Financeiros 2010 & N & $-2,30$ & 10,47 \\
\hline Lucro líquido em US\$ & 3 & 17,93 & 58,26 \\
\hline Patrimônio líquido ajustado em US\$ & 3 & 11,50 & 5,374 \\
\hline Rentabilidade legal em \% & 2 & 8,97 & 8,74 \\
\hline EBITDA em US\$ & 3 & Média & Desvio Padrão \\
\hline Dados Financeiros 2011 & N & $-3,55$ & 12,94 \\
\hline Lucro líquido em US\$ & 2 & 21,60 & 71,13 \\
\hline Patrimônio líquido ajustado em US\$ & 2 & 8,60 & 0,00 \\
\hline Rentabilidade legal em \% & 1 & 3,63 & 8,27 \\
\hline
\end{tabular}

Fonte: Elaborada pelos autores (2013).

Ao comparar os setores analisados, constatou-se que a mineração e serviços hospitalares obtiveram decréscimos na variável lucro líquido de 2010 em relação a 2011, na ordem respectivamente de $-91,2 \%$ e $-54,4 \%$. Assim, entre os três, o setor salineiro foi o que apresentou melhores resultados financeiros, já que seu lucro líquido cresceu em $11,11 \%$ como evidenciado na tabela 1. Isso certamente deve-se à típica inelasticidade econômica do sal, que o torna quase independente em relação aos demais setores aos quais se posiciona na economia.

\subsection{Grau de concentração}

Em outro momento, foi analisado o grau de concentração dos três setores: salineiro, mineração e serviços hospitalares. Segundo Lopes (2012), os índices de concentração são necessários para medir o nível de dominância que existe em um setor que desenvolve uma atividade em uma determinada região. Eles indicam que, quanto maior a concentração, menor o grau de concorrência. Os principais índices utilizados foram "Concentration Ratio" (CR), ou Razão de Concentração, que varia de 0 a 100. O outro índice é o "Herfindahl-Hirschman" (HH), que assume valor de 1 quando existe apenas uma empresa na indústria, configurando monopólio, e tem valores menores que $1 / n$ quando as empresas possuem participação igualitária no mercado. No caso, obtiveram-se os valores abaixo:

Quanto ao índice "Razão de Concentração", a análise da tabela 10, a seguir, permite inferir que a indústria salineira, nos anos estudados (2010 e 2011), foi a que se mostrou com maior concentração segundo a literatura, sendo representada por 0,911 e 0,9489, enquanto a mineração teve índices de 0,1319 e 0,0527. A saúde apresentou sua "Razão de Concentração" em 0,0316 e 0,0301, configurando-se como setores que também representam concentração, porém em menor nível que o salineiro. 
Tabela 10 - Índice razão de concentração - ()

\begin{tabular}{c|c|c|c}
\hline \multirow{2}{*}{ Ano } & \multicolumn{3}{|c}{ Setor } \\
\cline { 2 - 4 } & Salineiro & Mineração & Saúde \\
\hline 2010 & 0,911 & 0,1319 & 0,0316 \\
\hline 2011 & 0,9489 & 0,0527 & 0,0301 \\
\hline
\end{tabular}

Fonte: Elaborada pelos autores (2013).

O índice HH, aplicado no setor salineiro, composto por 33 empresas, nos anos de 2010 e 2011, teve valores 12,74519497 e 8,67207571, indicando ser oligopólio, conforme ilustrado na tabela 11, abaixo. Para Lopes (2012), trata-se de um setor altamente concentrado, já que o RN é responsável pela maior produção de sal marinho do país, chegando a cobrir até $95 \%$ da produção.

Tabela 11 - Índice Herfindahl-Hirschman $(\mathrm{HH})-\left({ }^{2}\right)$

\begin{tabular}{c|c|c|c}
\hline \multirow{2}{*}{ Ano } & \multicolumn{2}{|c}{ Setor } & Saúde \\
\cline { 2 - 4 } & Salineiro & Mineração & 0,0003448 \\
\hline 2010 & 12,74519497 & 0,00772634 & 0,00030789 \\
\hline 2011 & 8,67207571 & 0,00106607 & 0 \\
\hline
\end{tabular}

Fonte: Elaborada pelos autores (2013).

\section{CONSIDERAÇÕES FINAIS}

A pesquisa teve como objetivo comparar o desempenho empresarial do setor salineiro do RN no período de 2010/2011 com outros setores de mineração e serviços hospitalares que apresentam elevado grau de concentração. Foi possível constatar, por meio da análise aplicada nos aglomerados de mineração e serviços hospitalares, que houve um decréscimo no lucro dos dois setores de $-91,2 \%$ e $-54,4 \%$ respectivamente. Diferentemente das outras empresas, o setor salineiro foi o que melhor destacou-se financeiramente, pois apresentou crescimento no lucro líquido de $11,11 \%$. Um dos motivos explicado pelos salineiros foi que, em 2010, a tonelada de sal custava $R \$ 140,00$. Como a produção caiu em 2011, o preço da tonelada subiu para $R \$ 180,00$, o que levou o setor a um resultado financeiro positivo.

Mostrou-se um panorama do setor salineiro, no que se refere a variáveis relacionadas à gestão, inclusive com a criação de clusters a partir de suas características. A primeira análise de conglomerados consistiu nos indicadores sociais internos, externos e relacionados ao meio ambiente. Foi possível identificar que o primeiro e o segundo grupo mostraram maiores preocupações com os indicadores socioambientais, enquanto que o terceiro grupo apontou interesses iguais em todas as variáveis. Observou-se que os salineiros parecem entender que os investimentos em tais indicadores são necessários e que os mesmos valorizam as práticas sustentáveis e sociais, embora invistam, ainda, um percentual ínfimo da receita da empresa em questões como estas.

A segunda análise de cluster usa as variáveis financeiras: receita bruta, lucro líquido e ativo total. O primeiro grupo aumenta o nível de investimentos, sem, no entanto, ter acrescido nada nas suas receitas e lucros. O segundo grupo moderadamente aumenta as receitas e lucros, porém apresenta pouco crescimento em investimentos. $O$ terceiro grupo foi o que melhor mostrou desempenho financeiro em todas as variáveis. Diante disso, o setor salineiro mostra-se 
financeiramente em crescimento com resultados positivos para os anos em análise.

Averiguou-se por meio do teste $c^{2}$ (Qui-Quadrado) que as empresas dos clusters do agrupamento social e financeiro são independentes.

Ainda, ao que se refere ao desempenho financeiro, as salinas norte-rio-grandenses dispõem mais de capital próprio que capital de terceiros, tendo em vista que o setor foi representado com 4,95\% e 5,45\% para 2010 e 2011, o que mostra independência financeira e seguridade nas decisões empresariais. Outro aspecto analisado foram os prazos médios de venda, a renovação de estoque e compras, tendo sido observado que praticamente não existe variação nos anos levados em consideração. É necessário ressaltar que a atividade salineira quase não tem desperdícios de estoque, devido, provavelmente, ao alto consumo interno no país e as exportações.

$\mathrm{O}$ grau de concentração foi mais um ponto verificado entre os setores no estudo. Por meio dos índices $\mathrm{CR}$ e HH, foi possível verificar que o setor salineiro foi o que teve maior concentração, já que seus valores eram os que mais se aproximavam de um. Tais evidências mostraram que as salinas do RN representam um setor oligopólio, pois existe concentração distribuída entre as indústrias do ramo salineiro.

Uma das limitações da pesquisa foi a pequena quantidade de variáveis comuns para comparar os três setores. A despeito de ter procurado aprofundar os aspectos empresariais para o setor salineiro, a comparação com os dois outros setores deu-se com o uso de poucas variáveis financeiras. Entretanto, foi possível ter um resumo da situação financeira dos três aglomerados por meio do crescimento dos lucros e receitas apresentados.

Como sugestão para outros trabalhos, poderia se fazer uso de mais variáveis de natureza contábil/financeira, a fim de compará-las com os resultados empresariais obtidos.

\section{REFERÊNCIAS}

AGUIAR, L. Após crescimento setor salineiro do Rio Grande do Norte caminha a passos lentos. Novo Jornal, Natal, p. 1, 17, set. 2012. Disponível em: <http://www.riograndedonorte.net/2012/09/17/ apos-crescimento-setor-salineiro-do-rn-caminha-a-passos-lentos/>. Acesso em: 13 jan. 2013.

ALVES, K. R. C. P. Logística como ferramenta estratégica utilizada na minimização dos custos logísticos e maximização do desempenho econômico-financeiro: um estudo nas indústrias salineiras do Rio Grande do Norte. 2011. 136 f. Dissertação (Mestrado em Ciências Contábeis) - Programa multiinstitucional e Inter-Regional de Pós- Graduação em Ciências Contábeis (UnB, UFPE, UFPB E UFRN), João Pessoa, 2011.

BAIN, J. S. Industrial organization. New York: John Wiley, 1968.

BEZERRA, J. M. et al. Aspectos econômicos e ambientais da exploração salineira no Estado do Rio Grande do Norte. Revista de Engenharia Ambiental, p. 5, maio/jun. 2012.

CAPOBIANGO, R. P. Desempenho financeiro: um estudo com empresas de três diferentes setores. Revista de C. Humanas, Viçosa, v. 12, n. 1, p. 165-180, jan./jun. 2012.

CARREIRA, C.; LOPES, L. Are small firms more dependent on the local environment than larger 
firms? Evidence from Portuguese manufacturing firms. In: Fundação a Ciência e Tecnologia, 21., 2012, Coimbra, Portugal. Anais... Coimbra, Portugal: Faculdade de Economia da Universidade de Coimbra, 2012, p. 1-15.

CARVALHO, J. R. M. Medição de desempenho empresarial: um estudo nas organizações do setor salineiro no Estado do Rio Grande do Norte. 2007. 103 f. Dissertação (Mestrado em Ciências Contábeis) - Programa multiinstitucional e Inter-Regional de Pós-Graduação em Ciências Contábeis (UnB, UFPE, UFPB E UFRN), Natal, 2007.

COFF, R. W. The coevolution of rent appropriation and capability development. Strategic Management Journal, v. 31, n. 7, p. 711-733, 2010.

COOPER, D. R.; SCHINDLER, P. S. Métodos de pesquisa em administração. 10. ed. Porto Alegre: Bookman, 2011.

CORRAR, L. J. et al. Análise multivariada: para os cursos de administração, ciências contábeis e economia. São Paulo: Atlas, 2009.

DEVINNEY, T. M.; YIP, G. S.; JOHNSON, G. Using frontier analysis to evaluate company performance. British Journal of Management, 2009.

DONAIRE, D. Considerações sobre a influência da variável ambiental na empresa. Revista de Administração de Empresas, São Paulo, v. 34, n. 2, p. 68-77, mar./abr. 2011.

GARTNER, I. R. Modelagem multiatributos aplicada à avaliação do desempenho econômicofinanceiro de empresas. Revista Pesquisa operacional, v. 30. n. 3, p. 619-636, set./dez. 2010.

GHALAYINI, A. M.; NOBLE, J. S. The changing basis of performance measurement. International Journal of Operations \& Production Management, West Yorkshire, v. 16, n. 8, p. 63-80, 1996.

GOSCHIN, Z. et al. Specialisation and concentration patterns in the Romanian economy. Journal of applied quantitative methods, v. 4, p. 1-4, 2009.

GRAHAM, P. (Org.). Mary Parker Follett: profeta do gerenciamento. Rio de Janeiro: Qualitymark, 1997. 
HAIR, J. F. J. et al. Análise multivariada de dados. Porto Alegre: Bookman, 2005.

HARIF, M. A. A. M.; HOE, C. H.; AHMAD, M. I. The financial and non-financial performance indicators of paddy farmers' organizations in Kedah. Journal World Review of Business Research, v. 3, n. 1. p. 80-102. jan. 2013.

IBRAM. Instituto Brasileiro de Mineração. Informações e análises da economia mineral brasileira. 6. ed. 2011.

KAPLAN, R.S.; NORTON, D.P. A estratégia em ação: balanced scorecard. 4. ed. Rio de Janeiro: Campus, 1997.

KASSAI, S. Utilização da análise por envoltório de dados (DEA) na análise de demonstração contábeis. 2002. Tese (Doutorado em Ciências Contábeis) - Faculdade de Economia, Administração e Contabilidade, Universidade de São Paulo, 2002.

KEHINDE, J.S. Talent Management: Effect on Organizational Performance. Journal of Management Research, v. 4, n. 2. 2012.

KHANAFIAH, D.; SITUNGKIR, H. Social balance theory: revisiting Heider's balance theory for many agents, 2011.

KIBEREN, W. K.; MUSIEGA, D.; JUMA, S. Influence of brand management on rivalry for consumers in the mobile telecommunication industry. European Journal of Business and Management, $\mathrm{v}$. 5, n. 15, 2013.

KON, A. Economia industrial. São Paulo: Nobel, 1994

KUPFER, D.; HASENCLEVER, L. Economia industrial: fundamentos teóricos e práticas no Brasil. 2. ed. Rio de Janeiro: Elsevier, 2012.

LOPES, H. C. O setor calçadista do Vale dos Sinos/RS: um estudo a partir do modelo estruturaconduta-desempenho. Rio de Janeiro: Encontro de economia na PUC, 2012. 
LUNENBURG, F. C. Decision making in organizations. International Journal of Management, Business, and Administration, v. 15, n. 1, 2011.

MALHOTRA, N. K. Pesquisa de marketing: uma orientação aplicada. 3. ed. Porto Alegre: Bookman, 2001.

MARTINS, L. Renda mais alta do Norte e no Nordeste atrai planos de saúde. Folha de São Paulo, São Paulo, p. 1, 18 dez. 2011.

MATARAZZO, D. C. Análise financeira de balanços: abordagem gerencial. 7. ed. São Paulo: Atlas, 2010.

MELO, E. C.; ALMEIDA, F. M.; SANTANA, G. A. S. Índice de sustentabilidade empresarial (ISE) e desempenho financeiro das empresas do setor de papel e celulose. Revista de Contabilidade e Controladoria, Universidade Federal do Paraná, Curitiba, v. 4, n. 3, p. 95-112, set./dez. 2012.

MENEZES, E. A. C.; GUIMARÃES, T. A.; BIDO, D. S. Dimensões da aprendizagem em organizações: validação do dimensions of the learning organization questionnaire (dloq) no contexto brasileiro. RAM - Rev. Adm. Mackenzie, São Paulo, v. 12, n. 2, mar./abr. 2011.

NEELY, A.; BOURNE, M. Why measurement initiatives fail. Measuring Business Excellence, Bradford, v. 4, n. 4, p. 3-7, Dec. 2000.

OLIVEIRA, C. A. O. A dinâmica da estrutura da indústria de carne de frango no Brasil. 2011. 100 f. Dissertação (Mestrado em Agronegócios) - Universidade Federal do Rio Grande do Sul, Porto Alegre, Rio Grande do Sul, 2011.

RESENDE, M.; BOFF, H. Concentração industrial. In: KUPFER, D.; HASENCLEVER, L (Org.). Economia industrial: fundamentos teóricos e práticas no Brasil. Rio de Janeiro: Elsevier, 2012.

REVISTA EXAME MELHORES E MAIORES. 100 maiores região Norte - Nordeste. São Paulo: Abril, 2011.

100 maiores região Norte - Nordeste. São Paulo: Abril, 2012. 
SIESAL. Sindicato do Sal. Produção do sal marinho. Rio Grande do Norte, 2012. (Sindicato da indústria de extração do sal marinho no Estado do Rio Grande do Norte).

STEVENSON, W. J. Estatística aplicada à administração. São Paulo: Harbra, 2011.

TEDESCO, G. M. I. Transporte rodoviário de cargas: contribuição conceitual e metodológica à análise e classificação de mercados.2012. 202 f. Tese (Doutorado em Engenharia Civil e Ambiental) - Universidade de Brasília, Brasília, 2012.

WANDERLEY, C. A. et al. Um estudo sobre indicadores de desempenho para a perspectiva do aprendizado e crescimento do Balanced Scorecard. In: Congresso del Instituto Internacional de Costos, 8, 2010, Punta Del Leste, Uruguai. Anais... Uruguai: Congresso del IIC, 2010. 